\title{
EFEITO DE TRÊS ESPÉCIES DE GRAMÍNEAS FORRAGEIRAS SOBRE A ESTRUTURA DA PASTAGEM E DISTRIBUIÇÃO VERTICAL DE LARVAS INFECTANTES DE NEMATÓDEOS GASTRINTESTINAIS DE OVINOS
}

\author{
Danilo Gusmão de Quadros ${ }^{1}$, Américo Garcia da Silva SOBrinho ${ }^{2}$, Luís Roberto de

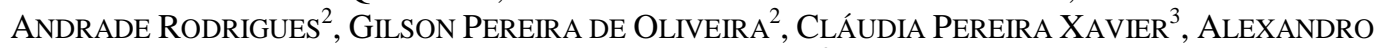 \\ PEREIRA ANDRADE ${ }^{3}$
}

\begin{abstract}
${ }^{1}$ Professor Doutor da Universidade do Estado da Bahia - Campus IX, Barreiras, BA, Brasil. uneb_neppa@yahoo.com.br. ${ }^{2}$ Professores Doutores da Faculdade de Ciências Agrárias e Veterinárias da UNESP, Jaboticabal, SP, Brasil. ${ }^{3}$ Engenheiros Agrônomos da Universidade do Estado da Bahia (UNEB) / Núcleo de Estudos e Pesquisas em Produção Animal (NEPPA), Barreiras, BA, Brasil.
\end{abstract}

O conhecimento da interação entre a disposição das larvas infectantes e o tipo de capim é fundamental nos estudos epidemiológicos e no controle das nematodioses gastrintestinais em ovinos. Objetivou-se, com este trabalho, avaliar os efeitos de três espécies de gramíneas forrageiras sobre a estrutura da pastagem e a distribuição de larvas infectantes (L3) de nematódeos gastrintestinais de ovinos deslanados no perfil vertical das gramíneas forrageiras, na época chuvosa do ano. Foram utilizadas 60 ovelhas, não periparturientes, naturalmente infectadas, distribuídas igualmente ao acaso em três piquetes de 2 ha formados com os capins andropógon, estrela-africana e
Tanzânia, manejados sob lotação contínua, de outubro de 2003 a março 2004, na Fazenda Santa Bárbara, município de Barreiras, Bahia. Os dados de três coletas entre dezembro de 2003 e março de 2004 foram analisados pelo SAS, em parcela subdividida, com 10 repetições. As larvas infectantes de Haemonchus spp. e Trichostrongylus spp. foram encontradas na forragem em todos os estratos do perfil vertical dos capins, sem um padrão definido de distribuição e sem diferença significativa entre capins. Pastagens com diferentes estruturas sob lotação contínua proporcionaram plenas condições para o desenvolvimento de larvas infectantes de ovinos.

PALAVRAS-CHAVE: Andropogon gayanus; Cynodon plectostachyus; Panicum maximum

\section{EFFECT OF THREE SPECIES OF FORAGE GRASSES ON PASTURE STRUCTURE AND VERTICAL DISTRIBUTION OF INFECTIVE LARVAE OF GASTROINTESTINAL NEMATODES OF SHEEP}

The knowledge of interaction between infective larvae setting and the type of grass is important to epidemiological studies and the control of gastrointestinal nematodes in sheep. The objective of this work was to evaluate the effects of three species of forage grasses on pasture characteristics and the vertical distribution of infective larvae (L3) of gastrointestinal nematodes of woolless sheep on the grasses during the rainy season. Sixty non-periparturients ewes were used, naturally infected, equally distributed on 2 ha paddocks sowed with Tanzania, star, and gamba grasses, managed under continuous grazing system, from October 2003 to March 2004, at Santa Bárbara farm, Barreiras-Bahia-Brazil. Data of three samples between December 2003 and March 2004 were analyzed by SAS, using split-plot design, with 10 replications. Infective larvae of Haemonchus spp. and Trichostrongylus spp. were observed on forage in all stratus of vertical layer of the grasses without a defined pattern. Pastures with different characteristics under continuous grazing system had good conditions for developing infective larvae of sheep.

KEYWORDS: Andropogon gayanus; Cynodon plectostachyus; Panicum maximum.

Ci. Anim. Bras., Goiânia, v.13, n.2, p. 139-144, abr./jun. 2012 


\section{INTRODUÇÃO}

As pastagens se constituem na mais econômica fonte de nutrientes para ovinos. Entretanto, nesse ecossistema, as verminoses se constituem no principal problema sanitário da criação, especialmente a causada por nematódeos gastrintestinais (AMARANTE, 2011). Ovinos mantidos em pastagens apresentam verminose durante todo o ano, com intensidade bem mais elevada no período chuvoso (GIRÃO et al., 1998).

A infecção do hospedeiro ocorre por meio de forragem contaminada com a forma larvar infectante (L3). Condições climáticas adequadas de umidade e temperatura favorecem o desenvolvimento de grande número de larvas infectantes que, uma vez ingeridas pelo hospedeiro, podem resultar na ocorrência de casos agudos de verminose (anemia, graus variados de edema submandibular, letargia, fezes escuras e perda de peso progressiva) (PINTO et al., 2009). Porém, a ingestão de menor número de larvas continuamente permite aos animais se adaptarem à infecção, ocorrendo sinais clínicos menos evidentes, mas afetam negativamente a taxa de crescimento e conformação de carcaça (KAWANO et al., 2001).

As diferenças na estrutura da pastagem de gramíneas forrageiras e as condições climáticas afetam o número e a disposição de larvas infectantes (MARTIN NIETO et al., 2003; CARNEIRO \& AMARANTE, 2008; QUADROS et al., 2010). Estrutura da pastagem é conceituada como a disposição horizontal e vertical sob a qual a forragem se apresenta aos animais, variando conforme o genótipo, idade da planta, época do ano e manejo.

A escolha da planta forrageira e o manejo da pastagem com ovinos devem favorecer as condições para rebrota rápida e abundante, um satisfatório valor nutritivo, uma eficiente utilização da forragem produzida e permitir a adoção de práticas para redução da população de larvas infectantes como parte do controle integrado de parasitos no rebanho.

Os objetivos deste trabalho foram avaliar os efeitos de três espécies de gramíneas forrageiras (capins Tanzânia, estrela-africana e andropógon), manejadas sob lotação contínua, sobre a estrutura da pastagem e a distribuição de larvas infectantes em diferentes estratos da parte aérea dos capins (0-15, $15-30$ e $>30 \mathrm{~cm}$ ), a contagem de OPG e os resultados da coprocultura de ovinos deslanados, na época chuvosa do ano.

\section{MATERIAL E MÉTODOS}

O trabalho foi conduzido na Fazenda Santa
Bárbara, município de Barreiras, Bahia $\left(12^{\circ} 05^{\prime}\right.$ lat. S; $45^{\circ} 20^{\prime}$ long. W), região fisiográfica de cerrados, área que vem apresentando grande crescimento da ovinocultura de corte. Foram utilizados três piquetes de aproximadamente 2,0 ha, formados há três anos e meio com os capins estrela-africana (Cynodon plectostachyus (K. Schum.) Pilger), Tanzânia (Panicum maximum Jacq. cv. Tanzânia) e andropógon (Andropogon gayanus Kunth. var. bisquamulatus cv. Planaltina), nos quais foram distribuídas ao acaso 20 ovelhas/piquete, nãoperiparturientes, naturalmente infectadas, com idades entre 2 a 4 anos, pesando em média $50 \mathrm{~kg}$.

As pastagens foram mantidas sob lotação contínua durante toda a estação de pastejo, de outubro de 2003 a março de 2004. À noite, os animais eram presos em instalações rústicas e, no início da manhã, entre 7:00 e 7:30 h, colocados nos piquetes, dispondo de água e mistura mineral ad libitum. As coletas de dados começaram a partir do final de dezembro de 2003 e início de janeiro de 2004, compondo um período de amostragem, tendo ocorrido mais dois períodos de avaliação nos meses de fevereiro e março de 2004.

A massa seca (MS) das frações lâminas foliares verdes (folha), colmos + bainhas (colmo) e material morto dos estratos de 0-15, 15-30 e > $30 \mathrm{~cm}$ da parte aérea dos capins foi determinada pelo corte, separação e secagem da forragem, colhida utilizando-se de um cubo estratificado, medindo 0,5 $\mathrm{m}$ de lado $\left(0,25 \mathrm{~m}^{2}\right)$, subdividido nas alturas estudadas, sendo amostradas 10 touceiras/piquete, seguindo linhas transectas imaginárias. A secagem das amostras foi realizada em estufa, com circulação forçada de ar, a $60^{\circ} \mathrm{C}$ por 72 horas (SILVA, 1998) e os valores obtidos utilizados para o cálculo da MS de cada fração por estrato $(\mathrm{kg} / \mathrm{ha})$.

A estimativa visual do percentual de cobertura do solo por gramíneas forrageiras, plantas daninhas e de solo sem cobertura vegetal foi mensurada por amostragem não-destrutiva, com quadrado de $1 \mathrm{~m}$ de lado, em 8 pontos/piquete e a leitura efetuada por dois observadores. O valor de cobertura de solo pelas gramíneas forrageiras foi multiplicado pela MS/ha de cada fração, para apresentação dos resultados conforme o grau de ocupação em cada capim estudado. A altura média das plantas foi medida com o auxílio de régua graduada em centímetros, em 20 pontos/piquete, seguindo linhas transectas imaginárias.

Conforme os dados meteorológicos, cotados pelo Instituto Nacional de Meteorologia (INMET), as chuvas no município concentraram-se de novembro de 2003 a março de 2004 (Tabela 1). 
Comparado à média histórica, o índice pluviométrico foi baixo nos meses de outubro e novembro. Após o mês de março, a precipitação decresceu significativamente, reduzindo sensivelmente a capacidade de suporte das pastagens.

TABELA 1 - Precipitação pluvial, temperaturas máxima, mínima e média no município de Barreiras Bahia, de setembro de 2003 a abril de 2004

\begin{tabular}{lcccc}
\hline \multicolumn{1}{c}{ Mês } & $\begin{array}{c}\text { Precipitação pluvial } \\
(\mathrm{mm})\end{array}$ & $\begin{array}{c}\text { Temperatura média } \\
\left({ }^{\circ} \mathrm{C}\right)\end{array}$ & $\begin{array}{c}\text { Temperatura } \\
\text { máxima }\left({ }^{\circ} \mathrm{C}\right)\end{array}$ & $\begin{array}{c}\text { Temperatura } \\
\text { mínima }\left({ }^{\circ} \mathrm{C}\right)\end{array}$ \\
\hline Setembro & 12,0 & 26,6 & 34,8 & 17,4 \\
Outubro & 34,0 & 28,3 & 35,4 & 20,1 \\
Novembro & 136,4 & 25,7 & 31,7 & 20,3 \\
Dezembro & 118,8 & 27,3 & 33,5 & 20,0 \\
Janeiro & 318,4 & 25,1 & 29,2 & 19,9 \\
Fevereiro & 201,2 & 25,5 & 30,0 & 20,0 \\
Março & 210,4 & 25,3 & 29,8 & 20,0 \\
Abril & 17,2 & 25,9 & 31,5 & 19,3 \\
\hline
\end{tabular}

Fonte: INMET - Barreiras

As fezes dos animais experimentais foram colhidas diretamente da ampola retal usando-se sacos plásticos identificados. Em seguida, foram levadas, em recipiente isotérmico com gelo, para o Laboratório do Núcleo de Estudo e Pesquisa em Produção Animal, do campus IX da UNEB, localizado a cerca de $15 \mathrm{~km}$ da Fazenda Santa Bárbara, onde foi realizada a parte de campo da pesquisa. Na contagem de OPG, utilizou-se solução saturada de cloreto de sódio $(\mathrm{NaCl})$ e se realizou leitura no microscópio em câmara McMaster (GORDON \& WHITLOCK, 1939). A coprocultura foi realizada segundo método de ROBERT \& O'SULLIVAN (1950), usando-se serragem úmida, ou vermiculita, como substrato. Não houve necessidade de calor suplementar, devido às boas condições de temperatura ambiente para a eclosão das larvas, as quais foram identificadas conforme KEITH (1953). O OPG médio obtido foi de 1228. Os resultados das coproculturas indicaram maior prevalência de larvas de nematódeos gastrintestinais dos gêneros Haemonchus spp. (20 a 65\%), Trichostrongylus spp. (5 a 72\%) e, em menor proporção, Cooperia spp. (0 a 12\%). Quanto à infecção mais restrita, houve baixa ocorrência de Oesophagostomum spp. (0 a 15\%) e Strongyloides sp. $(0$ a $3,5 \%)$.

A amostragem de forragem, para fins de levantamento demográfico das larvas infectantes L3, ocorreu até as $10 \mathrm{~h}$ da manhã, e o material foi imediatamente levado ao Laboratório do NEPPA/UNEB para extração das larvas infectantes. Uma sub-amostra de forragem de cada estrato (cerca de $200 \mathrm{~g}$ ) foi picada $(10 \mathrm{~cm})$ e colocada em um balde com $10 \mathrm{~L}$ de água por 18 horas. Em seguida, o capim foi retirado e o líquido remanescente permaneceu no balde por mais 6 horas, em temperatura ambiente, para sedimentar, sendo sifonado até um resíduo de aproximadamente $300 \mathrm{~mL}$, o qual foi colocado em um aparelho de Baermann. Após 24 horas, $15 \mathrm{~mL}$ do decantado foi coletado em um tubo de ensaio. Depois de, no mínimo, 24 horas em geladeira, $3 \mathrm{~mL}$ do fundo de cada tubo foi colocado em uma câmara de vidro, acrescido de 3 gotas de lugol fraco (1\%) e colocadas em microscópio ótico, com aproximação de 10X e 30X. As larvas infectantes L3 foram identificadas, conforme descrito por KEITH (1953), e quantificadas por meio de contagem. O número de larvas infectantes de nematódeos gastrintestinais encontrado na MS avaliada foi transformado por $\mathrm{kg}$ de MS.

Constatou-se que o material do aparelho de Baermann, oriundo de estratos com grande proporção de material morto, apresentou quantidades consideráveis de sujidades. Nesses casos, a retirada do líquido para análise ocorreu logo acima do sedimento escuro.

Os valores da contagem de larvas infectantes L3 foram transformados em $\log _{10}(\mathrm{x}+5)$ e submetidos à análise de variância pelo teste $\mathrm{F}$, sendo as médias comparadas pelo teste de Tukey, ao nível de 5\% de probabilidade, com desdobramento das interações significativas, utilizando o programa SAS (1996). Os dados foram analisados em parcelas subdidividas, estudando-se o efeito do capim na parcela e do estrato na sub-parcela, com 10 repetições e três períodos de amostragem.

\section{RESULTADOS E DISCUSSÃO}

O percentual de ocupação do solo por gramíneas forrageiras foi semelhante entre os capins 
testados ( $\mathrm{P}>0,05)$, com média de 56,3\% (Tabela 2). descoberto, enquanto os capins estrela-africana e A pastagem de capim-Tanzânia apresentou andropógon não diferiram entre si $(\mathrm{P}>0,05)$ (Tabela percentual mais elevado $(\mathrm{P}<0,05)$ de solo 2).

TABELA 2 - Cobertura do solo e altura média das plantas em pastagens dos capins Tanzânia, estrelaafricana e andropógon, sob lotação contínua de ovinos deslanados, na época chuvosa do ano

\begin{tabular}{|c|c|c|c|}
\hline \multirow[b]{2}{*}{ Capim } & \multicolumn{2}{|c|}{ Cobertura do solo $(\%)^{*}$} & \multirow[t]{2}{*}{ Solo descoberto (\%) } \\
\hline & Gramínea forrageira & Plantas daninhas & \\
\hline Capim-Tanzânia & $51,6 \mathrm{~A}$ & $12,9 \mathrm{~B}$ & $35,3 \mathrm{~A}$ \\
\hline Capim-estrela-africana & $59,7 \mathrm{~A}$ & $23,4 \mathrm{~A}$ & $16,9 \mathrm{~B}$ \\
\hline \multirow[t]{3}{*}{ Capim-andropógon } & $57,7 \mathrm{~A}$ & $19,0 \mathrm{AB}$ & $23,0 \mathrm{~B}$ \\
\hline & \multicolumn{3}{|c|}{ Altura média das plantas $(\mathrm{cm})^{*}$} \\
\hline & Dezembro-Janeiro & Fevereiro & Março \\
\hline Capim-Tanzânia & $48,7 \mathrm{~A} \mathrm{~b}$ & $72,2 \mathrm{~A} \mathrm{a}$ & $53,0 \mathrm{~B} \mathrm{~b}$ \\
\hline Capim-estrela-africana & $35,7 \mathrm{~A}$ a & $21,0 \mathrm{~B}$ a & $31,0 \mathrm{C} \mathrm{a}$ \\
\hline Capim-andropógon & $62,5 \mathrm{~A} \mathrm{ab}$ & $59,7 \mathrm{~A} b$ & $79,0 \mathrm{~A}$ a \\
\hline
\end{tabular}

* Médias seguidas de letras diferentes, maiúsculas na mesma coluna e minúsculas na mesma linha, diferem entre si pelo Teste de Tukey $(5 \%)$.

O capim-estrela-africana apresentou altura menor $(\mathrm{P}<0,05)$ do que os capins cespitosos, exceto na primeira avaliação no início da rebrotação, fato que se relaciona com os hábitos de crescimento distintos das gramíneas forrageiras estudadas (Tabela 2). Nenhum dos capins superou altura de $1 \mathrm{~m}$, máximo recomendado no manejo de pastagens com ovinos.

Houve interação significativa $(\mathrm{P}<0,05)$ entre a espécie de gramínea e o estrato da pastagem sobre a densidade de folhas, a qual foi maior $(\mathrm{P}<0,05)$ no estrato acima de $30 \mathrm{~cm}$, exceto no capim-andropógon $(\mathrm{P}>0,05)$, o qual apresentou valores bem baixos, em relação aos capins Tanzânia e estrela-africana (Tabela 3). Nesse estrato, os capins Tanzânia e estrela-africana apresentaram densidade de folhas dentro da variação de 30 a $100 \mathrm{~kg} / \mathrm{ha} / \mathrm{cm}$, relatada por QUADROS et al. (2010) para gramíneas forrageiras tropicais.

TABELA 3 - Densidade de folhas, colmos e material morto dos capins Tanzânia, estrela-africana e andropógon, manejados sob lotação contínua de ovinos deslanados na época chuvosa do ano

\begin{tabular}{|c|c|c|c|c|}
\hline \multirow[t]{2}{*}{ Capim } & \multicolumn{3}{|c|}{ Estrato $(\mathrm{cm})$} & \multirow[t]{2}{*}{ Média } \\
\hline & $0-15$ & $15-30$ & $>30$ & \\
\hline & \multicolumn{4}{|c|}{ Folhas (kg MS/ha/cm) } \\
\hline Capim-Tanzânia & $8,3 \mathrm{~A} \mathrm{~b}$ & $22,9 \mathrm{~A} \mathrm{~b}$ & $67,1 \mathrm{~A} \mathrm{a}$ & 33,1 \\
\hline Capim-estrela-africana & $6,6 \mathrm{~A} \mathrm{~b}$ & $10,9 \mathrm{~A} \mathrm{~b}$ & $74,3 \mathrm{~A}$ a & 30,6 \\
\hline Capim-andropógon & $5,0 \mathrm{~A} \mathrm{a}$ & $9,96 \mathrm{~A} \mathrm{a}$ & $21,0 \mathrm{~B}$ a & 11,6 \\
\hline \multirow[t]{2}{*}{ Média } & 54,6 & 14,4 & 6,43 & \\
\hline & \multicolumn{4}{|c|}{ Colmos (kg MS/ha/cm) ${ }^{*}$} \\
\hline Capim-Tanzânia & 66,2 & 68,8 & 28,5 & $55,7 \mathrm{~A}$ \\
\hline Capim-estrela-africana & 80,2 & 39,3 & 47,0 & $55,5 \mathrm{~A}$ \\
\hline Capim-andropógon & 17,6 & 18,7 & 5,0 & $12,7 \mathrm{~B}$ \\
\hline \multirow[t]{2}{*}{ Média } & $55,4 \mathrm{a}$ & $42,3 \mathrm{ab}$ & $26,9 \mathrm{~b}$ & \\
\hline & \multicolumn{4}{|c|}{ Material morto $(\mathrm{kg} \mathrm{MS} / \mathrm{ha} / \mathrm{cm})^{*}$} \\
\hline Capim-Tanzânia & $160 \mathrm{~A} \mathrm{a}$ & $136,0 \mathrm{AB}$ a & $17,0 \mathrm{~A} \mathrm{~b}$ & 105,0 \\
\hline Capim-estrela-africana & $145 \mathrm{~A} \mathrm{a}$ & $87,5 \mathrm{~B} \mathrm{a}$ & $64,3 \mathrm{~A} \mathrm{a}$ & 99,7 \\
\hline Capim-andropógon & $216 \mathrm{~A} \mathrm{a}$ & $214,0 \mathrm{~A} \mathrm{a}$ & $89,2 \mathrm{~A} \mathrm{~b}$ & 139,0 \\
\hline Média & 171 & 143,0 & 58,1 & \\
\hline
\end{tabular}


O capim-andropógon apresentou menor $(\mathrm{P}<0,05)$ densidade de colmos do que os capins Tanzânia e estrela-africana, em virtude da alta quantidade de material morto, que resultou em baixas densidades da fração verde (folhas e colmos) (Tabela 3).

A eventual redução da altura de manejo de gramíneas forrageiras tropicais, visando à diminuição da população de larvas de nematódeos na pastagem pela insolação, pode ser limitada pelo fato da estrutura apresentar alta densidade de colmos, resultando, segundo HUMPHREYS (1991), em alterações no comportamento ingestivo e redução da qualidade da dieta.

a)

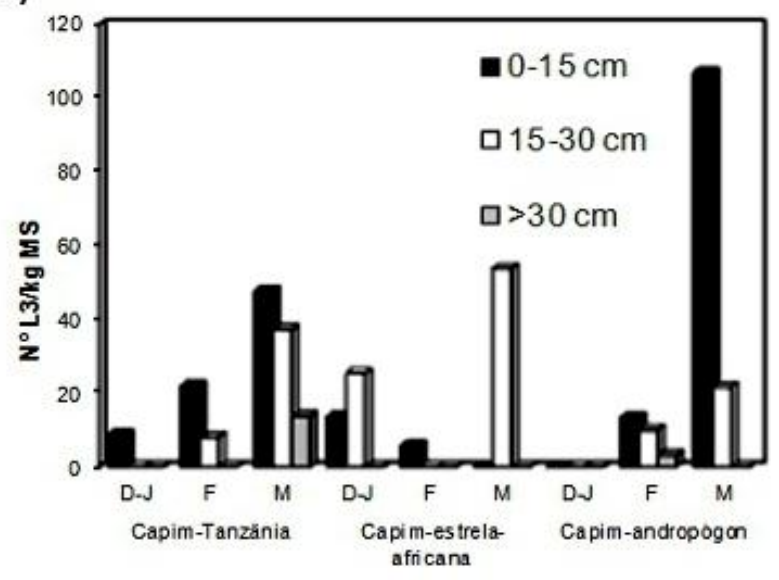

c)

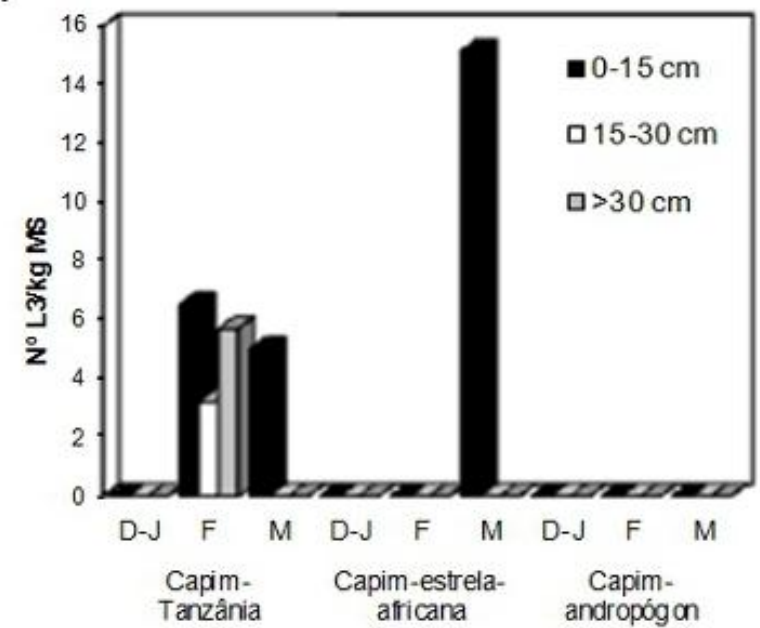

O capim-andropógon apresentou altas densidades de material morto, principalmente abaixo de $30 \mathrm{~cm}$, devido ao acúmulo de material não aproveitado no período seco do ano. No manejo da pastagem sob lotação contínua, geralmente a eficiência de utilização da forragem produzida é pequena, com a morte dos tecidos sombreados, principalmente das folhas mais velhas dos perfilhos (HODGSON, 1990).

O número de larvas infectantes de Haemonchus spp./kg MS foi influenciado pela interação estrato x época (Figura 1 - a), com distribuição variável em relação a cada tipo de capim.

b)
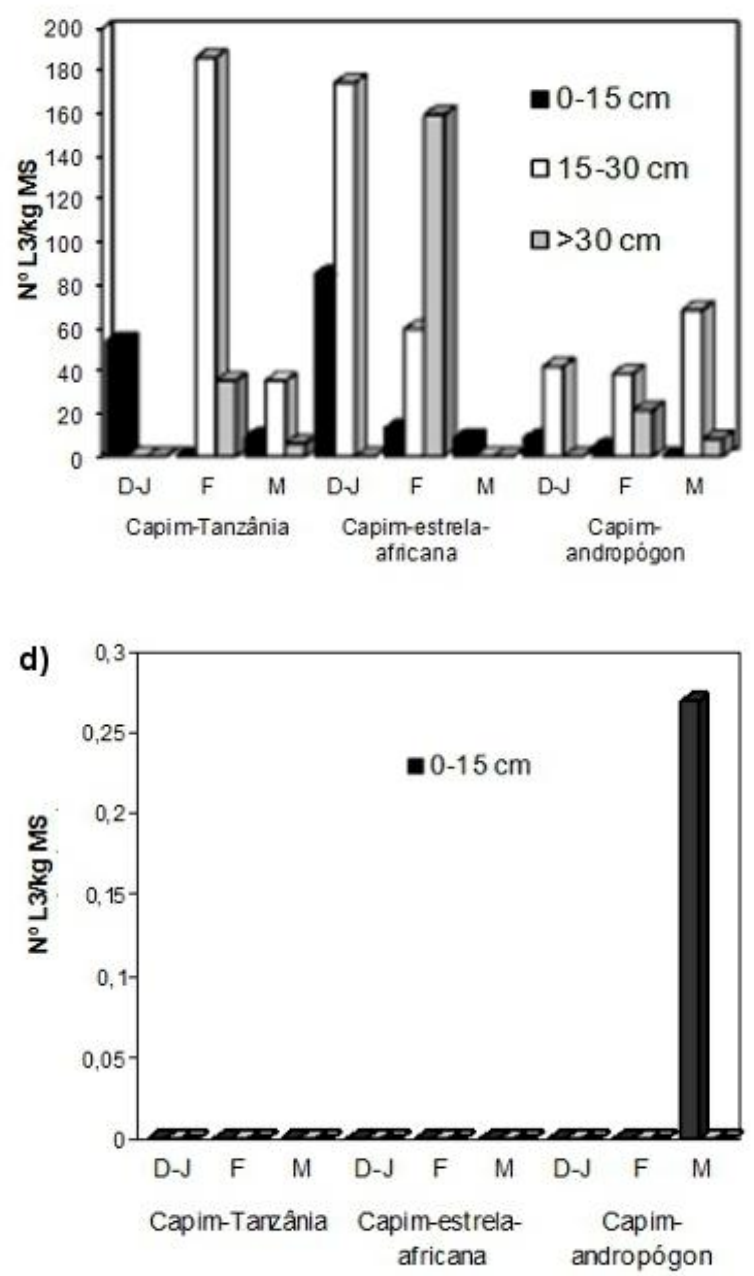

FIGURA 1 - Contagem de larvas infectantes de Haemonchus spp. (a) e Trichostrongylus spp. (b), Oesophagostomum spp. (c) e Strongyloides sp. (d) nos estratos de 0-15 (ロ), 15-30 (口) e >30 cm ( $\square$ ) dos capins Tanzânia, estrela-africana e andropógon, manejados sob lotação contínua de ovinos deslanados durante a época chuvosa. 
A habilidade das larvas infectantes em migrarem verticalmente é reconhecida, alcançando a parte superior das plantas na dependência da hora do dia (YAMAMOTO et al., 2004) e das condições ambientais, enquanto a migração horizontal é limitada a apenas $15 \mathrm{~cm}$ (ALMEIDA et al., 2005). Em geral, o ideal para o desenvolvimento das larvas é a ocorrência de temperaturas entre 22 e $26^{\circ} \mathrm{C}$, com umidade de $100 \%$, sendo o mínimo requerido em um microclima do dossel da pastagem de $85 \%$ (HANSEN \& PERRY, 1994).

A distribuição das larvas infectantes de Trichostrongylus spp. não seguiu padrão definido no perfil vertical dos capins (P>0,05) (Figura 1-b). É comum a ocorrência de grandes variações no número de larvas recuperadas em amostras de capim (AMARANTE et al., 1996). Chuvas torrenciais podem eliminar muitas larvas ou resultarem em umidade excessiva, impedindo a aeração da massa fecal e da camada superficial do solo, influenciando negativamente $o$ desenvolvimento das larvas (CARNEIRO \& AMARANTE, 2008). Por outro lado, as chuvas são fundamentais no rompimento da camada externa das síbalas de fezes, proporcionado condições à migração das larvas L3.

Foram encontradas na forragem predominantemente larvas infectantes de nematódeos gastrintestinais dos gêneros Haemonchus spp. e Trichostrongylus spp. (Figura 1), em nível semelhante ao observado por AMARANTE et al. (1996), em pastagem de capim coast-cross colhido a mais de $25 \mathrm{~cm}$ das fezes, sob lotação ovina e bovina, na época chuvosa do ano. Contudo, esse resultados foram inferiores aos valores observados por YAMAMOTO et al. (2004) nos capins forquilha, coast-cross e Tanzânia, sob lotação de 20 animais/ha. O número de ovos $/ \mathrm{m}^{2}$ e sua distribuição na pastagem são importantes fatores que influenciam o número de larvas na forragem (HANSEN \& PERRY, 1994).

Em menor número, foram encontradas larvas infectantes de Oesophagostomum spp. e Strongyloides $s p$. (Figura $1-\mathrm{c}, \mathrm{d}$ ). Dentre os cinco gêneros identificados nas coproculturas, apenas larvas de Cooperia spp. não foram recuperadas na forragem.

A presença de larvas infectantes nos estratos superiores da pastagem pode favorecer a ingestão de maior número de larvas. Conforme SYKES (1994), menos de 600 larvas infectantes consumidas diariamente podem ser responsáveis por reduções de até $50 \%$ no ganho de peso e na eficiência de utilização dos nutrientes pelos animais, além de queda no consumo de forragem, devido à nematodiose crônica.

$\mathrm{Na}$ época chuvosa do ano nos cerrados, pastagens dos capins Tanzânia, estrela-africana e Ci. Anim. Bras., Goiânia, v.13, n.2, p. 139-144, abr./jun. 2012 andropógon, sob lotação contínua de ovinos, proporcionaram condições adequadas ao desenvolvimento das larvas infectantes, apesar de apresentarem diferentes estruturas. A sobrevivência das larvas infectantes depende de um ambiente com umidade e sombra, pois a dessecação é o mais letal de todos os fatores climáticos (HANSEN \& PERRY, 1994).

$\mathrm{O}$ risco de ingestão de larvas pelos animais provavelmente é mais intenso no capim-estrelaafricana, cujo hábito de crescimento é prostrado e a faixa de pastejo é mais baixa, em relação aos capins Tanzânia e andropógon. Entretanto, FERNANDÉZ et al. (2001) observaram maior disponibilidade de larvas infectantes de Ostertagia ostertagi sobreviventes em gramíneas mais altas, presumidamente em consequência de melhor proteção ao calor e a dessecação.

Aparentemente a utilização de capins eretos, cespitosos, visando diminuição de nematodioses em ovinos, por si só, não foi eficaz, quando a pastagem é manejada sob lotação contínua, provavelmente pela ocorrência de reinfestação dos animais com a ingestão de larvas infectantes L3 oriundas dos ovos excretados nas fezes dos próprios animais.

\section{CONCLUSÕES}

A estrutura da pastagem foi bem diferente entre os capins, relacionando-se com o hábito de crescimento e manejo da pastagem. As larvas infectantes L3 não apresentaram padrão bem definido de distribuição nos diferentes perfis da pastagem dos diferentes capins. Contudo, considerando-se a altura de manejo adequada ao capim estrela-africana, o risco da ingestão de larvas pode ser maior.

\section{REFERÊNCIAS}

ALMEIDA, L.R.; CASTRO, A.A.; SILVA, F.J.M.; FONSECA, A.H. Desenvolvimento, sobrevivência e distribuição de larvas infectantes de nematóides gastrintestinais de ruminantes, na estação seca da baixada fluminense, RJ. Revista Brasileira de Parasitologia Veterinária, v.14, n.3, p.89-94, 2005.

AMARANTE, A.F.T. Why is important to correctly identify Haemonchus species? Revista Brasileira de Parasitologia Veterinária, v.20, n.4, p.263-268, 2011.

AMARANTE, A.F.T.; PADOVANI, C.R.; BARBOSA, M.A. Contaminação da pastagem por larvas infectantes de nematódeos gastrintestinais parasitas de bovinos e ovinos em Botucatu-SP. Revista Brasileira de Parasitologia Veterinária, v.5, n.2, p.65-73, 1996. 
CARNEIRO, R.D.; AMARANTE, A.F.T. Seasonal effect of three pasture plants species on the free-living stages of Haemonchus contortus. Arquivo Brasileiro de Medicina Veterinária e Zootecnia, v. 60, n. 4, p. 864-872, 2008.

FERNANDÉZ, S.; SARKUNAS, M.; ROEPSTORFF, A. Survival of the infective Ostertagia ostertagi larvae on pasture plots under different simulated grazing conditions. Veterinary Parasitology, v. 96, n. 3-4, p. 291-299, 2001.

GIRÃO, E.S.; GIRÃO, R.N.; MEDEIROS, L.P. Verminose em ovinos e seu controle. Teresina: Embrapa Meio Norte, 1998. 19 p. (Circular Técnica, 19).

GORDON, H.M.; WHITLOCK, H.V. A new technique for counting nematode eggs in sheep faeces. Journal of the Council of Scientific and Industrial Research, v.12, n.1, p.50-52, 1939.

HANSEN, J.; PERRY, B. The epidemiology, diagnosis and control of helminth parasites of ruminants, chap. 2 e 3. Nairobe:ILRAD:FAO, 1994. Disponível em <www.ilri.cgiar.org/Infoserv/Webpub/Fulldocs/X5492e00 $>$. Acesso em: 12 jun. 2004.

HODGSON, J. Grazing management: science into practice. London:Longman Scientific e Technical, 1990. 203p.

HUMPHREYS, L.R. Tropical pasture utilization, chap. 6. Cambridge:Cambridge University Press. p.88-106, 1991.

KAWANO, E.L.; YAMAMURA, M.H.; RIBEIRO, E.L.A. Efeitos do tratamento com anti-helmíntico em cordeiros naturalmente infectados com helmintos gastrintestinais sobre os parâmetros hematológicos, ganho de peso e qualidade da carcaça. Arquivos da Faculdade de Veterinária UFRGS, v. 29, n. 2, p. 113-21, 2001.

KEITH, R.K. The differentiation of the infective larvae of some commum nematode parasite of cattle. Australian Journal of Zoology, v. 1, n. 2, p. 223-35, 1953.
MARTIN NIETO, L.; MARTINS, E. N.; MACEDO, F. A. F.; ZUNDT, M. Observações epidemiológicas de helmintos gastrintestinais em ovelhas mestiças manejadas em pastagens com diferentes hábitos de crescimento. Ciência Animal Brasileira, v. 4, n. 1, p. 45-51, 2003.

PINTO, S.; BARROS, C.S.; SCOLARI, A.P.R.; SEBBEN, J.E. Larvas de Tricostrongilídeos em fezes de ovinos. Ciência Animal Brasileira, v. 10, n. 1, p.701706, 2009. (Suplemento 1). Disponível em: Disponível em:

$<$ http://www.revistas.ufg.br/index.php/vet/article/view/78 87/5725>. Acesso em: 28 Abr. 2012.

QUADROS, D.G.; SILVA SOBRINHO, A.G.; RODRIGUES, L.R.A.; OLIVEIRA, G.P.; XAVIER, C.P.; ANDRADE, A.P.; SOUZA E CUNHA, M.L.C.; FEITOSA, J.V. Verminose em caprinos e ovinos mantidos em pastagens de Panicum maximum Jacq. no período chuvoso do ano. Ciência Animal Brasileira, v.11, n.4, p.751-759, 2010.

ROBERT, F.H.S.; O’SULLIVAN, P.J. Methods for egg counts and larvae cultures for strongyles infecting. Australian Journal of Agricultural Research, v.1, n.1, p.99-02, 1950.

SAS INSTITUTE. SAS/STAT User's guide, version, 6 ed. Cary, 1996. 956p.

SILVA, D.J. Análise de alimentos: métodos químicos e biológicos. 2 ed. Viçosa: Editora Universitária, 1998. 221 p.

SYKES, A.R. Parasitism and production in farm animals. Animal Production, v.59, n.1, p.155-72, 1994.

YAMAMOTO, S.M.; MACEDO, F.A.F.; GRANDE, P.A.; MARTINS, E.N.; ZUNDT, M.; MEXIA, A.A; MARTIN NIETO, L. Produção e contaminação por helmintos parasitos de ovinos, em forrageiras de diferentes hábitos de crescimento. Acta Scientiarum., v. 26, n. 3, p. 379-84, 2004. 